\title{
The Collar Revolution: Everyday Clothing in Guangdong as Resistance in the Cultural Revolution*
}

\author{
Peidong Sun ${ }^{\dagger}$
}

\begin{abstract}
Scholars have paid little attention to Maoist forces and legacies, and especially to the influences of Maoism on people's everyday dress habits during the Cultural Revolution. This article proposes that people's everyday clothing during that time - a period that has often been regarded as the climax of homogenization and asceticism - became a means of resistance and expression. This article shows how during the Cultural Revolution people dressed to express resistance, whether intentionally or unintentionally, and to reflect their motivations, social class, gender and region. Drawing on oral histories collected from 65 people who experienced the Cultural Revolution and a large number of photographs taken during that period, the author aims to trace the historical source of fashion from the end of the 1970s to the 1980s in Guangdong province. In so doing, the author responds to theories of socialist state discipline, everyday cultural resistance, individualism and the nature of resistance under Mao's regime.
\end{abstract}

Keywords: clothing; dress resistance; the Cultural Revolution; Guangdong

After the founding of the People's Republic of China (PRC) in 1949, the Maoist regime intervened deeply in the everyday life of Chinese people, especially during the Cultural Revolution (1966-1976). This paper examines everyday clothing practices in China during the "ten year chaos" - an area that has received little scholarly scrutiny despite the fact that dress is one of the most notable forms of cultural expression. Although it has been argued that the Cultural Revolution "froze fashion by increasing the desire to conform" in many cultural domains, ${ }^{1}$ I maintain instead that it increased people's desire to resist, giving expression to diversity, individuality, gender distinction and geographical fusion. An examination of everyday dress habits during the political movement will lead to a better understanding of the legacies of Maoism in China's cultural domain. The diversity and individualism that burst forth in the late 1970s and that has

\footnotetext{
* This paper is translated from Chinese to English by Shan Windscript with Antonia Finnane.

$\dagger$ Department of history, Fudan University. Email: spd@fudan.edu.cn.

1 Obukhova, Zuckerman and Zhang 2014, 559. 
grown ever since did not happen overnight, as is commonly assumed; as this examination of apparel shows, its foundation was laid during the Cultural Revolution.

In studies of contemporary China, little attention has been paid to the impact of Maoism ${ }^{2}$ on ordinary life, and especially to how Maoist ideologies influenced how people dressed during the Cultural Revolution. ${ }^{3}$ By and large, the Cultural Revolution has been interpreted as a history of elite politics and mass movements. Current scholarship on the Cultural Revolution still centres predominantly on power struggles ${ }^{4}$ and mass movements ${ }^{5}$ - especially those of the workers, ${ }^{6}$ sent-down youth ${ }^{7}$ and the Red Guards ${ }^{8}$ - but says little about ordinary people's everyday life during this major political event.

Mainstream accounts typically portrayed the stereotyped homogeneity of Mao-era clothing during the Cultural Revolution, describing Chinese people as "blue ants," perpetually clad in blue cotton clothing, shuttling back and forth to their workplaces on a daily basis. ${ }^{9}$ For example, the everyday clothing in Michelangelo Antonioni's Chung Kuo (China, 1972), ${ }^{10}$ and Lucy Jarvis' The Forbidden City $(1973)^{11}$ clearly portrays this stereotype. ${ }^{12}$ More recent works have focused on the importance of the "everyday" in our understanding of the Mao era, shedding new light on the crucial role of consumer goods and behaviour in a changing and reproducing social order. ${ }^{13}$

Compared to Shanghai, a place that has drawn much scholarly attention thanks to the many published memoirs of the Cultural Revolution, ${ }^{14}$ Guangdong province has remained under-examined despite its unique geographical position. Owing to Guangdong's proximity to Hong Kong, Macau and

2 I use Maoism to describe the practices of resistance that arose directly from a set of interrelated features under Maoist rule. The everyday life of people living under authoritarian regimes with centralized economic planning differs greatly from that of people in democratic societies with a market economy. For studies of private life in Stalinist Russia that focus on the impact of Stalinism on individuals' inner worlds and family relations, see Hellbeck 2006; Figes 2007; Fitzpatrick and Lüdtke 2009. See Demick 2009 for research on North Korea that places emphasis on the plight of people under Kim Il-Sung's regime, as evidenced by defectors. New research on the Third Reich has paid attention to the spiritual oppression and exploitation of youth under Hitler (Klemperer 2000; Knopp 2002; Allert 2009.).

3 Pickowicz and Walder 2006 shows how political events changed ordinary people's lives in urban and rural society, and how they acted in turn, and provides a good insight into the Maoist forces and legacies of the 1960 s and 1970 s.

4 MacFarquhar 1981; Wang, Nianyi 1988; Jin, Chunming 1995; MacFarquhar and Schoenhals 2006; Teiwes and Sun 2007; Liu, Qingfeng 1996; Guo, Wang and Han 2009; Dong and Walder 2011.

5 Wang, Shaoguang 1995a.

6 Perry and Li 1997; Li, Xun 2015.

7 Bonnin 2010.

8 Walder 2009; Chan 1985; Rosen 1981; Lee 1978; Tang 2003; He 2010. The sixth volume of The History of the People's Republic of China (1949-1981), which focuses on the Cultural Revolution, provides no information on the daily lives of ordinary people. See Li, Danhui, and Shi 2008.

9 Guillain 1957, 1-19.

10 Antonioni 1972.

11 Jarvis 1973.

12 Liu, Zhijun 2002, 39.

13 Wang, Shaoguang 1995b; Lei 2000; Xu, Bei 2006.

14 Jin, Dalu 2011. 
Taiwan, and because of its links to those places through the Canton Fair, its politics, economy and culture have been influenced by the West to a greater degree than any other place in mainland China. This permeability creates the context and the possibility for other expressions of individualization and difference that I will discuss in the following sections. Elsewhere, I have examined Guangdong people's everyday clothes and fashion during the Cultural Revolution, ${ }^{15}$ and "bizarre clothes" with respect to state discipline at that time. ${ }^{16}$

Although mainstream ideologies significantly determined dress codes, the degree of resistance in the way people dressed within their established norms during the Cultural Revolution should not be underestimated: over the course of the revolution, people's understanding of beauty and fashion pluralized and personalized. This paper aims to provide new dimensions to current understandings of the Cultural Revolution by focusing on the neglected topic of everyday dress. Based on a study of Guangdong province, it first examines the influence of Maoism on clothing between the 1960s and 1970s, revealing the historical foundations of the creative burst of Chinese fashion from the end of the 1970s to the 1980s. Second, it responds to theories related to socialist state discipline, everyday cultural resistance, individualism and the nature of resistance under Mao's regime. I argue that a reconsideration of people's everyday clothing practices during the Cultural Revolution reveals that the agency for individual resistance and expressions of diversity at the grassroots was in fact much greater, even during the heyday of the Mao era, than previously believed.

\section{Research Method and Sources}

Primary data for this paper were gathered from semi-structured in-depth interviews with 65 registered Guangdong residents. The interviews explored how individuals used clothing as a means of resistance during the Cultural Revolution, the specific social contexts that shaped their behaviour, and their subjective perceptions of their social contexts. My informants had all worked or studied in Guangdong during the Cultural Revolution, and were chosen for this study using "life history case studies" 17 and "birth cohort theory." 18 Most were born between the 1930s and 1950s. There were 33 male and 32 female participants. They were drawn from 15 of Guangdong's 21 prefecture-level cities. In order to maximize the range of cases across age, gender, education, occupation and location, they have been methodically sorted. Between March 2005 and October 2006, I conducted one to two interviews per person, with each interview lasting about one to two hours. Most of the photographs used in this paper were 
provided by the interviewees. Some of the photos were provided by the Integrated Education Gallery of the Sun Yat-sen University library. ${ }^{19}$

\section{Dress Resistance}

"There is no power without potential refusal or revolt." 20 Everyday dress resistance is often manifested in small actions that are "unorganised, unsystematic and individual, opportunistic and self-indulgent." 21 Such resistance is described by Michel de Certeau as a "tactic" that is "an art of the weak;" in the everyday context, individuals can use "popular tactics" to articulate their acts of resistance. ${ }^{22}$

Whereas both de Certeau and James Scott look at resistance and weapons of the weak in societies marked by inequality and exclusion (either class differences in advanced capitalism or in colonial/post-colonial rural societies), I wish to apply their ideas about resistance to a society filled with both "agents and victims" whose roles were fluid and in constant flux. ${ }^{23}$

On the one hand, dress resistance in the Cultural Revolution is marked by a sense of visibility. People complied with mainstream dress conventions during the Cultural Revolution because acting in line with the dominant political and ideological orders gave them a sense of security, much as they used revolutionary names: "more popular and thus safer." 24 Clothing was also a cultural practice of everyday resistance: personalized, gendered and rationalized clothing practices such as altering the sleeves, collars, waists and trouser leg openings can be seen as major expressions of people's resistance.

On the other hand, people may have been adopting the subtle forms of contestation we see in the "weapons of the weak" but without knowing exactly whose exercise of power they needed to resist and against whom they needed to protect themselves. The Cultural Revolution created a mutually injurious society (huhai shehui 互害社会), where different forces took turns to wield power and the boundaries between victim and perpetrator were permeable. People who could be persecuted owing to inappropriate clothing behaviour included Red Guards, village headmen, production team leaders, workplace leaders, union presidents, neighbours, colleagues, peers, friends and even spouses and children. Expressions of resistance had to remain not only more subtle but potentially even more "ambiguous" than in the cases named by Scott and de Certeau. ${ }^{25}$ Ambiguous expressions of resistance can actually protect those who resist by allowing them to deny that they were in fact engaged in any type of subversion or critique.

19 See the library's website at: http://202.116.65.75/web/EN/home. Accessed 10 May 2016.

20 Foucault 1981, 253.

21 Scott 2008, 50.

22 De Certeau 1984, 26-37.

23 Siu 1989.

24 Obukhova, Zuckerman and Zhang 2014, 576.

25 Thornton 2002. 
Dress resistance in the Cultural Revolution was conditioned by a sense of political uncertainty under Maoist rule, which was also a major source of people's feelings of insecurity. ${ }^{26}$ Therefore, people's dress resistance was a silent and subtle undertaking rather than an overt form of political action or confrontation. However, as my informants asserted during our interviews, they felt that their choice of clothing silently "spoke" to the public. Everyday dress resistance, like Hakim Bey's "nomadology," provided my informants with a "temporary autonomous zone," that is, a site of individual resistance for "an era in which the State is omnipresent and all-powerful and yet simultaneously riddled with cracks and vacancies." ${ }^{27}$ In short, everyday dress resistance under Maoist socialism was a persistent phenomenon. Although its effectiveness was limited, it should not be neglected. Oppressed in a climate of political uncertainty, people's strategically performed acts of resistance could bring them a sense of autonomy and individuality.

\section{Defying Economic Deprivation: the Invention and Use of the Detachable-Collar Shirt, Gunnysack Shirt, and Fertilizer Trousers}

Three factors were behind the monotony of everyday clothing during the Cultural Revolution: economic deprivation, political discipline and moral punishment. ${ }^{28}$ Economic deprivation led to uniformity of clothing as, without material resources and bound by social and political rules, people were limited in their freedom to choose what to wear and had to rely on their own resourcefulness and imagination. Therefore, dress resistance was, first and foremost, a reaction against material scarcity.

The emergence and popularity of detachable-collar shirts in Chinese cities and towns reflected ordinary people's desire for "face" even at a time when money was short. It was also called the "economic collar" (jingji ling 经济领) or "thrifty collar" (jieyue ling 节约领). It consisted of a half-collar shirt with two shoulder strap attachments that were there to avoid any possible embarrassment arising from the use of an easily dislodged detachable collar. One of the interviewees, who worked as a bench worker at a car repair factory during the Cultural Revolution, recalled an embarrassing moment when talking about his wedding day:

I got married in August. The weather was hot. After I brought the bride home, I took off my lapel-collar suit coat (fanling wen zhuang 翻领文装) because I felt very hot. Then people saw my detachable-collar shirt. They all started laughing at me; my wife started to cry, refusing to enter the "bridal chamber" with me. My mother-in-law was scolding me, saying I'd never worn anything but cheap work clothes when we were dating, too. How embarrassing! I felt like a drowning mouse! $!^{29}$

29 Interview with retired worker, Guangzhou, November 2006. 
Detachable collar shirts were popular in the late 1970s and early 1980s. They looked good and were easy to wash. They also saved on fabric. Typical attire for men at that time was a plain coloured, detachable-collar shirt under a handknitted sweater; for women, the detachable-collar shirt was often made of floral fabric. In short, detachable-collar shirts are an indication of how individuals used available sartorial resources to construct their individual identities and to shape their self-esteem in specific social contexts.

The gunnysack shirt was invented by rural cadres who exploited limited local resources to their own advantage. The cadres were able to obtain gunnysacks, a rare local source of fabric, from their production teams (shengchandui 生产队). They ripped out the seams of the gunnysacks and re-fashioned them into Chinese-style shirts with two big pockets at the waist. A primary school principal in Guangdong witnessed three ranks of cadres (commune cadres, team cadres and village cadres) attending a conference, all wearing gunnysack shirts: "If you saw someone wearing a gunnysack shirt, you would know that he must be a ranking cadre. It was a sign of power and prestige!" 30 Apart from rural cadres, urban blue-collar workers also wore gunnysack shirts. A man who worked as a porter at the Guangzhou Machinery Factory during the Cultural Revolution recalled that, "We porters also used rice gunnysacks to make clothes. This type of material was durable, warm, and saved on the use of cotton. It even saved on material for protective sleeves. You could say that it gave you three things for the price of one." 31

For rural cadres and urban porters alike, wearing gunnysack shirts was an expedient response to the shortage of fabrics and cloth coupons. The gunnysack shirt is a demonstration of the flexibility and capacity for innovation on the part of ordinary people within the limitations imposed by their material conditions. At the same time, shirts made from hemp sacks came to be an indication of the wearer's position in the political order and their corresponding social identities.

The emergence of fertilizer trousers was related to China's chemical import projects. After the Lin Biao Incident 林彪事件 in 1971, the Central Committee adjusted their policies of ultra-leftism; also in the same year, the PRC took its seat in the United Nations, leading to an increase in international contact. Following US President Nixon's visit, Western countries began to establish connections with China and foreign trade and international economic cooperation proliferated. In the new national and international political economic climate, advanced petrochemical technology was introduced to China in an effort to solve the country's clothing issues. With the support of the vice-premier, Li Xiannian 李先念, four chemical fibre projects and 13 fertilizer projects were launched. The main fertilizer was urea (carbamide) imported from Japan. ${ }^{32}$

30 Interview with retired middle school director, Guangzhou, November 2006.

31 Interview with retired worker, Guangzhou, October 2006.

32 Shan 2001, 587. 
In rural Guangdong, urea was assigned to local supply and sales cooperatives in bags made of chemical fibre nylons, similar in texture to cotton silk. At the time, a family's annual allocation of cloth coupons was not adequate to clothe the whole family. Commune and team cadres therefore used various means to purchase the fertilizer bags from the supply and sales cooperatives to make clothes. Each bag cost about four cents, and two bags were enough to make a pair of trousers. Many commune cadres wore trousers made of these fertilizer bags, winning admiring and envious looks from the peasants.

Envy was accompanied by humour. The front and back of the fertilizer bags were marked with words such as "urea" and "Japanese xx corporation." When the bags were made into trousers, the words appeared around the waistband of the trousers and were very prominent. The effect is recorded in popular jingles of the time: "Japan is in the front, urea at the back; behold the crotch, nitrogen - 45 per cent!" (Qianmian shi Riben, houmian shi niaosu; zaiwang dangli kan, han dan liang 45\%! 前面是日本, 后面是尿素; 再往裆里看, 含氮量 45\%!). And, again: "Little commune cadres all in nylon trousers/Japan is in the front, urea at the back/ Some dyed black, others dyed blue/ for commune members none at all" (Gongshe xiaoganbu, chuanzhe ninlong ku. Qianmian Riben chan, houmian shi niaosu. Ranheide, ranlande, jiu shi meiyou sheyuande 公社小干部, 穿着尼龙 裤。前面日本产, 后面是尿素。染黑的, 染蓝的, 就是没有社员的). ${ }^{33}$

Fertilizer trousers, like gunnysack shirts, were invented by rural cadres as markers of social identity to differentiate themselves from ordinary peasants in everyday contexts. It shows that those with special access to items were able to "wear" that access to signal their power in the centrally planned economy. I argue that in the 1970s, the Cultural Revolution had created a great levelling between cadres and the masses, and between managers and workers, across all workplaces. Such clothing strategies, ridiculous as they may sound today, were used by local political elites to construct their identities. In addition, fertilizer trousers provided a window to modernity for rural Chinese people in the 1970s. The fact that a mere fertilizer package was made of soft and comfortable nylon fabric gave rise to speculation about the wealth of Japan and the West, in contrast to mainland China where even material for clothing was extremely scarce.

The above three cases show some of the ways in which clothing became a site of resistance in people's everyday life, and a means by which social actors could build their identities. Constrained by the political system, individuals could be strategically obedient, or they could make a variety of conscious choices, by using their initiative and coming up with inventions. These inventions reflect the cleverness and humour of the people in Guangdong at that time, as well as expressing their preoccupation with the exercise of social power and identity formation. 


\section{Resisting Political Discipline: the "Colour Revolution" and Personalized Dress}

For most of the 65 interviewees, the olive-green army uniform was seen to be the desirable outfit during the Cultural Revolution. But, a few of them - even people belonging to the five red categories - explicitly resisted, or showed contempt for, the uniform. One interviewee, who was a shipyard worker in Guangzhou, said that he had never worn an army uniform or army cap, and when his younger brother gave him one as a gift, he sent it to be dyed blue at a dye house. ${ }^{34}$

His dislike of army uniforms arose from something that happened to his co-worker during the Cultural Revolution. At that time, the trousers they were allocated all had wide crotches, which many young workers found ugly. Those with sewing machines at home were able to alter the trousers to ensure a better fit. The interviewee's co-worker altered the bottoms of his trousers to make them skinnier. Red Guards confiscated and destroyed his trousers, and wrote big character posters to criticize his "rotten bourgeois" thinking. After that, the interviewee felt antagonistic towards army uniforms and the people who wore them. In his view, clothes and fashion in the Cultural Revolution originated from the "new fundamentalism" of the extreme Mao cult. During that "dark age," army uniforms conformed to the revolutionary trend but in his view were ridiculous. Having put himself at odds with the current line being propagated, he dreaded the potential consequences if it were discovered that he had dyed his army uniform blue. When a green army uniform was dyed blue-grey, it looked similar to a navy uniform; and at the shipyard where he had worked, from the director down to the workers, many people were navy veterans and wore navy uniforms. The interviewee obtained a certain psychological security from wearing a blue-grey navy uniform.

This case reveals that in a society where individuals' private living spaces are closely monitored by political forces, their forms and means of resistance are different to those in a market economy society. In China during the Cultural Revolution, clothing, as a form of visual text that is directly visible, became a tool by which Chinese individuals struggled for self-expression and representation. ${ }^{35}$ By dressing in accordance or discordance with the mainstream norm, ordinary Chinese people expressed their acceptance of or opposition to the existing order. In doing so, they effectively challenged the dominant dress discourse dictated by the larger socio-political force. The deliberate colour manipulation was indeed a way of expressing resistance.

Personalized dress was a reaction to the national suppression of "bizarre clothes." On 7 June 1964, the Liberation Daily published an article to spark mass debate about, and mass criticism of, the wearing of strange clothes, declaring that such attire was a manifestation of an "unhealthy lifestyle" and a vulgar 
Figure 1: Cun zai in Suits

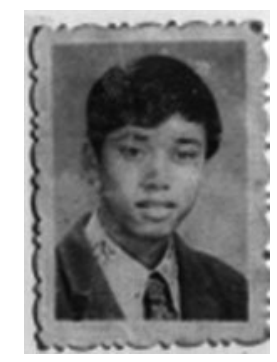

Source:

Photographed by his relative in Guangzhou 1972, offered by the interviewee.

reflection of "decadent, declining bourgeois ideology." 36 After this nationwide mass debate and criticism, unconventional clothes gradually disappeared from people's daily lives. Under this political pressure, the nation established an aesthetic of "only the political is beautiful" (zhengzhi wei mei zhuyi 政治唯美主义), to make people oppose unconventional clothes and legitimate the criticism of people's clothing choices in the name of class struggle. ${ }^{37}$

One interviewee who admitted that he was ahead of his time and bold in his attire, was criticized for being cun zai 寸仔(Cantonese for bad person) by his classmates and teacher because he once wore clothes he received as gifts from his Hong Kong relatives. Wearing black straight-legged jeans and a bright blue T-shirt made him the subject of criticism by the school authorities who viewed him as a "negative example." But he admitted that those clothes made him feel good and vigorous. He believed that dress choice should be a personal freedom, and should not be interfered with. He recounted one heroic act with much pride: in 1972, he ventured to a photographic studio, opened by his relative, to have his picture taken wearing a bright red tie given to him by his relatives in Hong Kong, even though he knew that people were not allowed to wear ties at that time. ${ }^{38}$

Some other interviewees recalled how they had racked their brains for ways in which they could alter their work uniforms in order to convey a sense of personality and taste. For a while, the trend among factory workers was to wear blue work clothes. One worker used a piece of wood to give her jeans a scrubbed look. She always found ways to make her clothes more "form-fitting" in order to show off her figure. ${ }^{39}$ In a centrally planned economy that produces a limited range of clothing, individualization can itself be a form of resistance to the

38 Interview with retired worker, Guangzhou, October 2006.

39 Zhai 2008, 261. 
existing power structure - although this would not necessarily be the case with individualization in a liberal capitalist society.

According to Yunxiang Yan, Maoist China was "the first stage in the Chinese path to individualization," when the Chinese people came "out of the shadow of the ancestors but re-molded as a rust-less screw" in the collectivist programmes of social engineering; the "individuality, independence, and desires of the Chinese individual at the tail end of Maoist China were both weakened and strengthened to certain degrees." ${ }^{40}$ Although people's private lives were dominated by Maoism, my interviewees in general sought to carve out a space for self, individualism and personal aesthetic views.

The dissatisfaction expressed by the three interviewees above with the dress order of the Cultural Revolution is indicative of two things. First, none of them fully abided by the highly homogenizing dress conventions that promoted uniformity and denied individuality. Second, the ways in which they sought to personalize their clothes show that individualism and aesthetic instinct still existed in their manner of dress. They paid attention to their private lives, implying the existence of subjectivity. Here, management of private life had become an effective means for resisting public power.

\section{Resisting Moral Punishment: Gendered Clothes and the "Revolution on the Collar"}

Ordinary life during the Maoist era, as epitomized by women's clothing in the Cultural Revolution, has been regarded as a climax of masculinization and puritanical asceticism..$^{41} \mathrm{It}$ is therefore not difficult to understand why some scholars consider Chinese women's interest in beauty and fashion as a new, post-Mao phenomenon. ${ }^{42}$ Jean Kunz posits that, since the Cultural Revolution, beauty and fashion have been defined by the dominant political ideologies; beauty and fashion were singularized and people's creativity was suppressed before being reactivated by the economic reforms of the $1980 \mathrm{~s} .{ }^{43}$ Under the new, proletarian morality of the PRC, the CCP denigrated women who did not abide by the conventions of revolutionary dress, labelling them as deviant (bu zhengjing 不正经), dishonest (bu laoshi 不老实), flirtatious (fengsao 风骚), vain (aimu xurong 爱慕虚荣), fox spirits (hulijing 狐狸精) who worship foreign things, or bourgeois ladies (zichanjieji xiaojie 资产阶级小姐).

However, Hung-Yok Ip questions the idea that women's interest in and pursuit of beauty is a newly developed trend of the post-Mao era, and argues that, "an interest in feminine beauty ... was always present in the [Chinese] revolutionary process," and the strategic use of appearance was important for revolutionary 
politics. ${ }^{44}$ Tina Mai Chen discusses how Mao suits and military uniforms helped to produce a new subjectivity under the new socio-political system from 1949 to 1966. ${ }^{45}$ Antonia Finnane examines clothes and fashion in the Cultural Revolution from the perspectives of gender, class and nationalism, revealing that fashion has been an important part of Chinese people's everyday life since the late imperial period. ${ }^{46}$ Even in the revolutionary era, Chinese women still managed to find ways to resist what my respondents termed the androgenization of clothing implemented by the party-state.

Fashion is a means of artistic and political expression. The use of tattoos can be understood as an opposition to the commodification of bodies. ${ }^{47}$ As such, the collar revolution during the decade of turmoil can be seen as Chinese women's opposition to the homogenizing and oppressive dress order by revealing their unique senses of gender- and self-identity. In Dongguan 东莞, one interviewee recalled that zhiqing 知青 (sent-down youth) women especially liked to alter their collars, from V-shaped, square and pointed collars to the more fashionable round-shaped, stand-up, boat and wing collars. For Chinese men, turned-down collars, turtleneck and stand-up collars were fashionable preferences. ${ }^{48}$ A 1975 photograph of a group of zhiqing women taken in Yuexi 粤西, Guangdong, proves that the wing-collar was very popular among the female zhiqing community. ${ }^{49}$

The ways in which women from different social classes manifested resistance to Cultural Revolutionary norms, and the intensity of the resistance, varied. In her memoir, Zhang Hanzhi 章含之, a translator at the Ministry of Foreign Affairs, recalls: "I always wanted to do something different with my clothes. Before attending a UN meeting once, I picked a piece of turquoise-coloured fabric no one else would have chosen that [at the time] - and had it made into a coat, with a round collar instead of a square one. I also added a grey detachable fur collar." 50 Zhang was criticized on this account and labelled as "unconventional and individualistic" (biao xin liyi 标新立异). However, she was not deterred. In the lobby of the Great Hall of the People, there was a mirror next to the cloakroom. After hanging up her coat, she always checked herself in the mirror before entering the conference venue. This made her the target of criticism for engaging in bourgeois activities. In fact, the dress resistance practised by Zhang was something beyond the realm of possibility for ordinary people. Before being appointed as a translator for the Ministry of Foreign Affairs by

44 Ip 2003, 330. Fashion (self-adornment as disguise) could be useful for the CCP's underground activities, and dressing up could help revolutionaries carry out their mission and to construct a positive image of the CCP. See Ip 2003.

45 Chen 2001.

46 Finnane 2008.

47 Fisher 2002.

48 Interview with retired local official, Guangzhou, August 2006.

49 See group photo of female zhiqing advanced delegation of congress, photographed by Zhou Zeming in Maoming 1975, at the Integrated Education Gallery of the Sun Yat-sen University library.

50 Zhang, Hanzhi 1994, 88-99. 
Mao Zedong in 1971, Zhang had been his English teacher for seven years. Ordinary people would have been criticized and denounced or would have lost their lives for donning the sort of "unconventional" clothes she wore. 51

During the Cultural Revolution, the collar was also used as a symbol of identity for brides. Although women wore dark coloured outfits on their wedding day, they used pink collars to intimate their newlywed status. ${ }^{52}$ In addition, women refashioned their sleeves, altering ordinary long sleeves into puff (灯笼 袖 denglong xiu), bell (喇叭袖 laba xiu), ruffle (泡泡袖 paopao xiu) and petal sleeves (花瓣袖 huaban xiu).

There is a long history of altering collars and sleeves to convey a sense of individual and gender identity within the framework of the CCP's highly politicized “red aesthetics." On Women's Day in Yan'an 延安 in 1940, more than 500 students from the Chinese Women's University performed a dance wearing Lenin suits that they had tailored themselves. This created a great stir in Yan'an at a time when everyone, from Party members to students, wore the Eighth Route Army uniforms. ${ }^{53}$ Using the collar as sign of struggle, people reacted to the state's overt moulding of the masses, appropriating and manipulating available symbols into oppositional forces. Collars and sleeves symbolized a personal, private space where people could entertain "an illusion of power and control." 54 They desired a free, easy and even sentimental private life rather than a panpoliticized everyday existence centred on class struggle.

Women also used hair-ribbons and hair clips to express their sense of self. One interviewee recounted that she had devoted much time to thinking about how to make her hair look different. She also designed and made colourful hair strings. A photograph she provided shows her in a short haircut, parted on the side from the left to the right in an attempt to create a sort of asymmetrical style, with a little pigtail fastened on the top-right side of her head. The hair tie she used to fasten the pigtail was made by herself, using threads she had teased from her worn-out floral-patterned clothes - presents she had received from her Hong Kong relatives. ${ }^{55}$

Women with more financial resources could afford colourful hair clips to adorn themselves with. Their short revolutionary haircuts were often cleverly and nicely decorated with hair clips. ${ }^{56}$ The hegemonic revolutionary taste had not extinguished people's desire to express themselves and their tastes, and they would find all kinds of ways to do just that by using jacket coverings, zippers, white masks, ${ }^{57}$ and even glass fibres. ${ }^{58}$

58 Zhu 2006. 
During the Cultural Revolution, dresses and skirts were introduced to the Chinese public via officially sanctioned political gatherings and celebrations. In 1974, China participated for the first time in the Asian Games, held that year in Tehran, Iran. At the opening ceremony, the Chinese women athletes entered the stadium wearing the Jiang Qing 江青 dress. This type of dress retained traces of a uniform, but because it was a frock and generally made of a soft material like imitation silk or satin cotton, it tended to show the curves of the female body shape. ${ }^{59}$ Jiang Qing's sufficient political privileges empowered her to "revolutionize" Chinese women's fashion - within certain boundaries. Her venture into design reveals the scarcely perceptible growth of women's gender awareness in the revolutionary age. ${ }^{60}$

Furthermore, the local government of Guangdong permitted women to wear dresses when welcoming foreign guests. One interviewee told me a story about his Indonesian cousin, who was a secondary school student in Guangzhou during the Cultural Revolution. She and her classmates were required by their school to wear skirts when greeting foreign guests. Some of her classmates had to borrow hers in order to comply with this rule. ${ }^{61}$

Clothes often serve as a barometer of a country's political atmosphere, and as such, skirts and dresses were the weather vanes for women's fashion in Mao-era China. The rise of the Soviet-style "Blazy" dress (布拉吉 bulaji) in China was closely related to the state of Sino-Soviet relations in the 1950s. The changing collars, the re-emergence of skirts and dresses, and the colours and patterns of shirts could effectively reflect public perceptions of political, economic and social life in later decades. Guangdong people's everyday dress habits demonstrated that while the larger clothing culture of the time hindered people from freely expressing their identities and individualities, collars, sleeves, waists and trouser-legs provided them with spaces in which their acts of resistance could occur.

\section{Resisting Geographical Barriers: the Inflows of Foreign Dress and Fashion}

Individual clothing resistance in Guangdong was possible in large part because of the province's geographical proximity to Hong Kong, and because it was the site of the Canton Fair, ${ }^{62}$ which gave sporadic but targeted official permission to the (at least temporary) adoption of Hong Kong/Western/foreign goods for the sake of increasing trade. ${ }^{63}$ It also exposed Guangzhou residents to a variety of

59 Zhang, Hong 2004.

60 Ibid.

61 Interview with retired university professor, Guangzhou. October 2006.

62 A biannual trade fair founded in Guangzhou in 1957, the Canton Fair continued to attract foreign businessmen to China throughout Cultural Revolution. They brought with them not only trading opportunities but also exotic clothing.

63 By the 1960s and 1970s, the Party had adopted a policy that explicitly advocated "adopting long-term plans and making full use of acquiring foreign currencies for importing equipment sets and gears." See Ma 1979. 


\section{Figure 2: Family Picture}

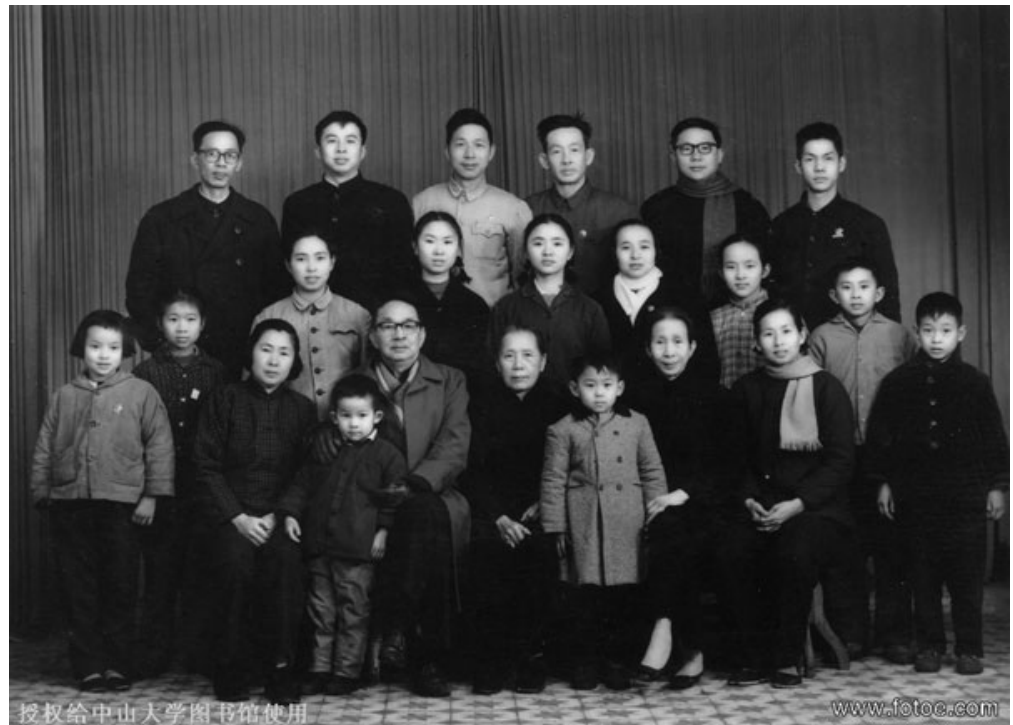

Source:

Photographed by Ruxiong Liang in Guangzhou 1968, Integrated Education Gallery of the Sun Yat-sen University library.

sartorial possibilities and stylistic innovations ${ }^{64}$ that, in a sense, may have provided them with a ready-made toolkit of "repertoires of resistance" from which to draw. ${ }^{65}$

To the people of Guangdong, Hong Kong, Macau and also Taiwan were no doubt windows on to the world of fashion. Figure 2 shows a Guangdong/ Hong Kong family photo taken at the Yanfang Photographic Studio in Guangdong before the 1968 Spring Festival. Three generations of 22 family members are shown, variously sitting and standing. One can identify where they are from just by looking at the clothes they are wearing: those with rather conservative hairstyles and stern facial expressions who are wearing Chinese-style tunic suits with Mao badges pinned to their chests are apparently from Guangdong; in contrast, those who are in Western-style suits with scarves tied around their necks are the relatives from Hong Kong.

Figure 3 shows another photograph of daily life in Guangzhou, taken during the later period of the Cultural Revolution, where one can sense the influence of Hong Kong, Macau and Taiwan. The young woman in the photograph is wearing a pullover sweater with bell-bottoms (laba $k u$ 喇叭裤), looking quite stylish

64 In the 1950s and 1960s, the Guangzhou municipal government and Guangdong provincial government often invited delegations from Hong Kong and Macau to attend the Chinese National Day celebrations. In the 1960s, the total number of Hong Kong visitors to mainland China averaged 347,000; that number slightly decreased to 253,198 in 1967 and 1968, but from 1970 began to grow again. See Zhang, Baojun, and Zhao 1997.

65 Tilly 1991. 


\section{Figure 3: Citizens Visit a Park}

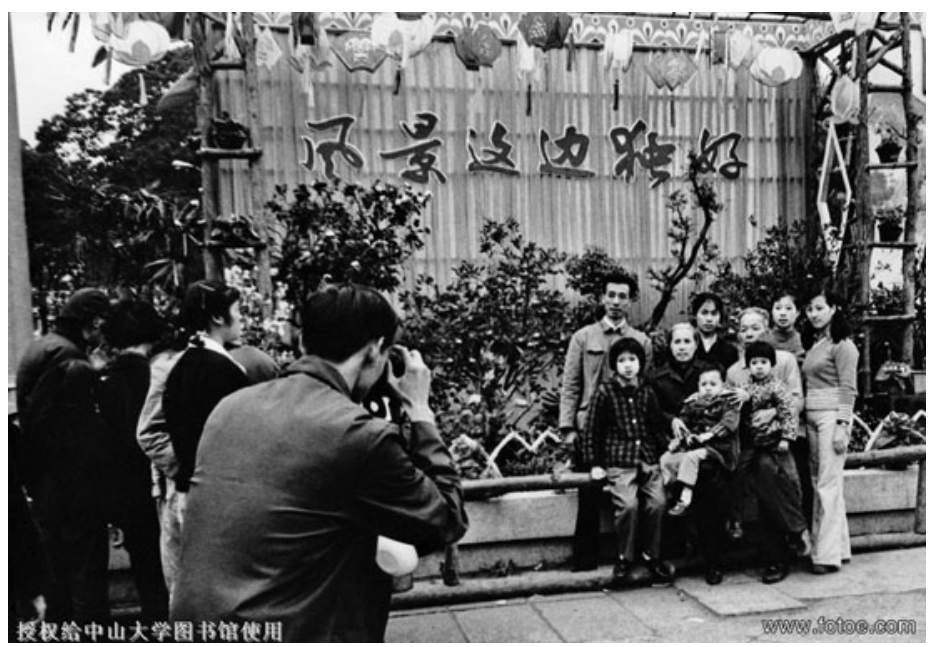

Source:

Photographed by Minsheng Meng in Guangzhou 1975, Integrated Education Gallery of the Sun Yat-sen University library.

even by today's standard. Other women in the photograph are wearing shirts that feature slightly wider-cut necks. The colours and decorative patterns of their skirts were criticized as “bourgeois patterns” (zichanjieji huawen 资产阶级花纹) at the beginning of the Cultural Revolution.

Among the 65 interviewees, 49 of them, that is, 75.38 per cent, said that they or their family members had received clothes as gifts from Hong Kong, Macau, Taiwan, the USA or South-East Asian countries during the Cultural Revolution. According to these data, Guangdong maintained a relatively high level of clothing exchange with the outside world. Clothing from outside of Guangdong, which was more stylish than the local clothing and made of better quality fabric, presented a cultural challenge to China, throwing down the gauntlet to the revolutionary fashion that predominated in the province.

At a time when the street scene in mainland China was dominated by highly politicized revolutionary clothing, Guangdong's encounter with foreign fashion elements made the province a special place in the country, where everyday clothing styles looked quite different to those of inland Chinese cities. Until the end of the 1970s, when family members who lived outside the mainland returned to visit Shanghai, they brought with them clothes as gifts for relatives. ${ }^{66}$ On 16 May 1976, as the tenth anniversary of the launch of the Cultural Revolution was being celebrated across the nation, Guangdong's political atmosphere was noticeably different. For example, a photograph taken in Harbin shows hundreds of thousands of people celebrating the anniversary together, conveying a strong 
Figure 4: Parade in Harbin
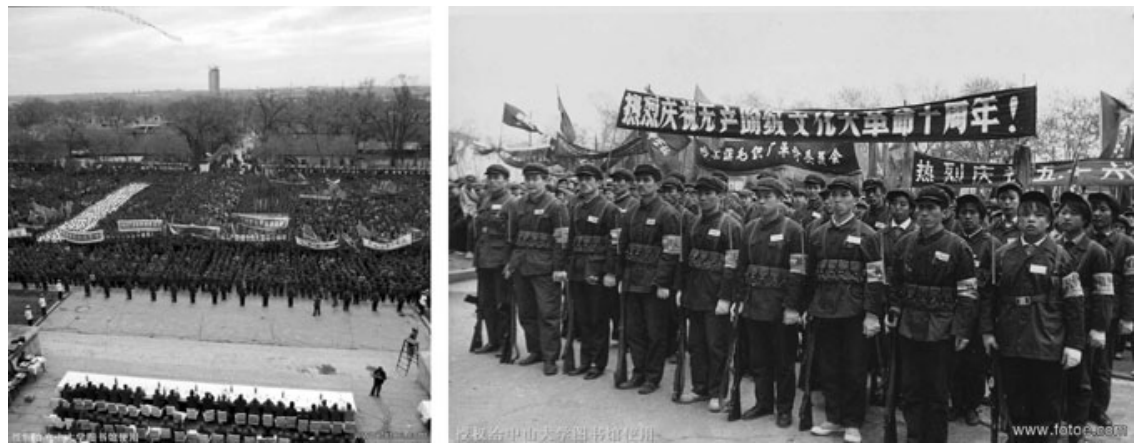

Source:

Photographed by Zhensheng Li in Harbin 1976, Integrated Education Gallery of the Sun Yat-sen University library.

\section{Figure 5: Parade in Guangdong}
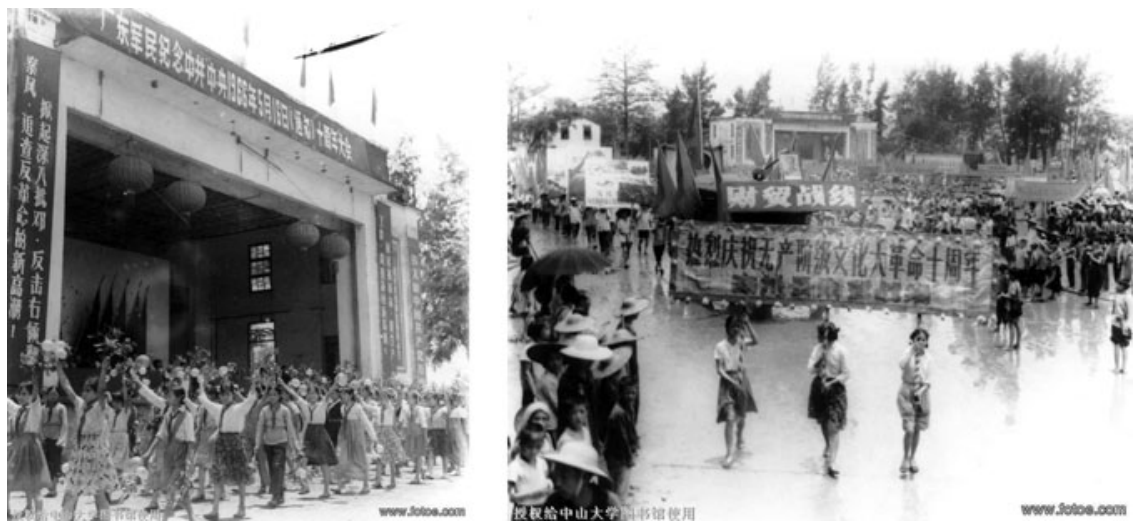

Source:

Photographed by Zeming Zhou in Guangzhou/Gaozhou 1976, Integrated Education Gallery of the Sun Yat-sen University library.

political atmosphere (Figure 4). The first two rows of the podium are occupied by officials. Under the podium steps, six soldiers stand with their hands behind their backs, facing the podium with their backs to the masses. Several fully armed soldiers stand guard on the rally ground; behind them is a sea of people, the revolutionary masses. In contrast, a picture taken on the same day at the Army and People's Commemoration Rally (Figure 5), jointly organized by Guangzhou and Gaozhou 高州, shows more than 20 female students walking past a podium wearing red scarves and holding flowers. Some of them are wearing frocks, others skirts, all in different colours and patterns, with more than a dozen decorative designs. In another photograph, taken in Gaozhou on the same day, three girls holding a banner walking in the front are all wearing skirts. Many bystanders 
among the crowd, however, are barefoot, wearing straw hats or holding umbrellas (also Figure 5). Even when taking the contrast in local climates into account, the difference between Harbin and Guangzhou is profound.

What the overseas relatives of Guangdong residents brought into their lives were more than just some colourful, fancy second-hand clothes. They also brought the possibility of a different lifestyle in a different society, prompting people to think about what freedom, individuality and "self" meant. "Alien" (tazhe 他者) clothes also meant an alternative (linglei 另类) fashion for Guangdong people. Many interviewees said that their wedding outfits were bought in Hong Kong, or given to them as gifts by their Hong Kong relatives. The colour, style and quality of their imported wedding outfits would attract much attention and admiration from their local communities. People could not help but think that, "[Guangzhou and Hong Kong] are so close. How come things from Hong Kong are so much better than ours? How come we don't have them here?" 67 In short, Guangdong's unique geographical location is one important external factor that has contributed to the contrast between Guangdong's clothes and fashion and those of other, inland Chinese provinces. Having been subjected to more foreign influences than other parts of China, many people in Guangdong had the opportunity to make alternative fashions a point of reference for everyday clothing. In contrast, inland Chinese people had little exposure to foreign cultures during the Cultural Revolution and as a result their overall clothing styles tended to be much less diversified than those of Guangdong.

The four types of dress resistance that I have discussed are interrelated. No authority was left unchallenged; rather, it would always face resistance and struggle from individuals or groups. There are many reasons for, and forms of, dress resistance. What I have discussed here are individual means of resistance to economic deprivation, to political discipline, to moral punishment and to geographical isolation.

\section{Conclusion and Discussion}

On the surface, clothing and fashion in the first three years (1966-1969) of the Cultural Revolution appear to have been hegemonic. The mainstream dress preferences of the time were army uniforms, work uniforms, Zhongshan 中山 suits, Red Guard uniforms and Lenin suits. ${ }^{68}$ However, this article has demonstrated that while clothes and fashion may have indeed seemed to be unvarying between 1966 and 1976, there were also undercurrents of resistant forces beneath the surface. Such forces of resistance paved the way for the radical fashion explosion in China in the 1980s. Many of the "new fashions" that burst onto the scene at the end of the 1970s were nothing more than the existing unofficially recognized 
everyday clothes practices that ordinary people had been quietly carrying out in the 1960s and 1970s. Everyday dress resistance during the Cultural Revolution showed its profound accumulative consequences later: "Things brewed in the Seventies, blossomed in the Eighties, and bore fruit in the Nineties." 69

The conclusion of this article is two-fold. First, the unique geographical location of Guangdong province played an important role in softening or weakening the dominant political power over local people's everyday life, prompting a clothing culture that was more diverse than that in other places where people could not express their "hidden desires." Second, Guangdong people's dress revolution was carried out by using everyday clothing as a means of resistance. Dress resistance is an expression of opposition to the existing dress order and a way of expressing diversity, individuality, gender distinction and geographical fusion. By challenging the mainstream ideology and the power of conventional dress culture/political or revolutionary culture, Guangdong people's dress revolution carved out a new space for cultural resistance practices or a new transgressive culture.

How could there be dress resistance under an authoritarian political system and planned economy? First, it had something to do with people's changing identities and their explorations of subjectivity. Personal identity has been an allconsuming concern for the Chinese government. In 1949, the CCP urged Chinese people to decide their own fate and thereby take control of the fate of the nation. In the 1950s, the Party began systematically to institutionalize and standardize social constructions. By the 1960s, the Chinese subjectivity which the Party itself had created had become problematic. The memorable Cultural Revolution slogan, "down with the Yanwang 阎王 (King of Hell), liberating the small devils," meant that people from all revolutionary classes could oppose and challenge the institutional structures that had constrained their lives. As a result, "heterodox currents of thought" (yiduan sichao 异端思潮) emerged one after another during the Cultural Revolution. ${ }^{70}$ Dress was one of the most convenient tools people could use to express their various senses of "self."

Second, compared to the early phase of the Cultural Revolution, the CCP's control over public opinion slightly relaxed in the late 1960s and early 1970s. This paved the way for the fashion liberation and revival that took place in the late 1970s and early 1980s. In the early 1970s, while the CCP on the one hand still advocated that personal consumption should adhere to the "revolutionary" and "collective" principles, on the other hand it stressed that revolutionary and collective principles did not mean over-simplification. ${ }^{71}$ Meanwhile, China's international circumstances began to improve. The large-scale import of foreign technologies and equipment led to an improvement in the quality of people's clothing, and ultimately laid a solid foundation for resolving people's food and clothing problems in the 1980 s. ${ }^{72}$

72 Shan 2001, 587. 
Third, the emergence and development of fibre technology provided the material conditions for the later diversification of clothing. Dacron (的确良 diqueliang) was first developed successfully in Guangdong. Although the production of Dacron was impeded during most of the Cultural Revolution, by 1973 it had become one of Guangdong's top exports. ${ }^{73}$ Compared to cotton, Dacron is very strong, highly durable and quick drying, and its local production unquestionably opened the door for the personalization and diversification of dress during the Cultural Revolution.

Finally, the core reason why people used dress as a means of resistance is a natural, human wish to pursue their desires and normal lifestyles. Other social phenomena during the Cultural Revolution have demonstrated the resilience of human nature: the "great criticism" campaign led to the a resurgence of and a fad for writing traditional poetry; ${ }^{74}$ manuscript copies of romantic and pornographic fiction rose considerably during the decade; ${ }^{75}$ and many Shanghainese privately traded revolutionary propaganda for profit. ${ }^{76}$ When cadres, educated youth and workers were sent down to Sunan 苏南 (rural areas of southern Jiangsu province), they took with them technologies and market information that benefited the local communities. ${ }^{77}$

\section{Acknowledgement}

The author acknowledges the financial support of the Chinese National Philosophy and Social Science Foundation (Project ID: 15ZDB051). She thanks Ning Wang, Nicolas Herpin, Deborah S. Davis, Guobin Yang and two anonymous reviewers for helpful comments on earlier drafts. She also thanks Shan Windscript and Antonia Finnane for their flawless translation. This paper forms part of a major project by the Chinese National Social Sciences: "Collection and arrangement of data and documentary research on the sentdown campaign during the Cultural Revolution."

\section{Biographical note}

Peidong Sun is an associate professor in the department of History at Fudan University. Her main areas of research focus on comparative and historical sociology, the Chinese Cultural Revolution, and social history and institutional change during the 20th century. She has been published in Open Time (Guangzhou), Twenty-first Century (Hong Kong), Youth Studies (Beijing), as well as many other peer-reviewed journals. Her latest books include Fashion

73 “Fangzhi gongye zhi” (Textile industry's records), Guangzhou shi difang zhi, http://www.gzsdfz.org.cn/ gzsz/06A/fz/frameest.htm. Accessed 6 February 2007.

74 Mei 2007.

75 Liu, Dong 2005.

76 Jin, Dalu 2011, 309.

77 Fei 1992, 24. 
and Politics: Fashion in Guangdong Province during the Cultural Revolution (People's Publishing House, 2013) and Who Will Marry My Daughter? The Parental Matchmaking Corner in the People's Square of Shanghai (Chinese Social Sciences Press, 2012, 2013).

\begin{abstract}
摘要: 长期以来, 学界对毛主义的力量和遗产, 尤其是毛主义对文革时期民 众日常着装的影响及其后果少有研究。本文提出被视为同质化和禁欲主义 达到高潮的文革日常着装, 自文革初期起, 就成为多样化、个性化、性别化 和地域化的一个抗争之场。文章表明民众如何透过有意无意的日常着装 “越界”行为表示抗争，并以此显示动机、阶层、性别和地域层面的差异。 以 65 个文革亲历者的口述史和大量被访者提供的照片为基础，作者揭示 了 1970 年代后期至 1980 年代以广东为代表的中国着装时尚井喷式爆发 的历史原因; 其次, 通过日常着装反抗的研究，回应了社会主义国家规训、 日常文化抗争以及毛体制下个人主义和个体抗争的性质等相关理论.
\end{abstract}

关键词: 着装选择; 着装抗争; 文化大革命; 广东

\title{
References
}

Ai, Xiaoming, and Bu Wei. 2009. "Shijue sheyun: Ai Xiaoming, Bu Wei duitan" (Visual-social movement: a conversation between Ai Xiaoming and Bu Wei). In Chuanbo yu shehui xuekan 10, 197-212.

Allert, Tilman. 2009. The Hitler Salute: On the Meaning of a Gesture (Jefferson Chase (trans.)). New York: St Martin's Press.

Antonioni, Michelangelo. 1972. Chung Kuo, Cina [documentary film]. RAI.

Bey, Hakim. 1991. T.A.Z.: The Temporary Autonomous Zone, Ontological Anarchy, Poetic Terrorism. New York: Autonomedia.

Bonnin, Michel. 2010. Shiluo de yidai: Zhongguo de shangshan xiaxiang yundong 1968-1980 (The Lost Generation: China's Rustication Movement 1968-1980). Ouyang Yin (ed.). Beijing: The Encyclopaedia of China Publishing House.

Cai, Xiang. 2008. "Qishi niandai: modai huiyi" (The seventies: memories of the last generation). In Bei Dao and Li Tuo (eds.), Qishi niandai (The Seventies). Hong Kong: Oxford University Press, 331-347.

Chan, Anita. 1985. Children of Mao: Personality Development and Political Activism in the Red Guard Generation. London: Macmillan.

Chen, Tina Mai. 2001. "Dressing for the Party: clothing, citizenship, and gender-formation in Mao's China." Fashion Theory 5(2), 143-171.

Croll, Elisabeth. 1995. Changing Identities of Chinese Women: Rhetoric, Experience, and Self-perception in Twentieth-century China. Hong Kong: Hong Kong University Press.

De Certeau, Michel. 1984. The Practice of Everyday Life. Berkeley, CA: University of California Press.

Demick, Barbara. 2009. Nothing to Envy: Ordinary Lives in North Korea. New York: Spiegel and Grau.

Deng, Gang. 2008. "Wo cengjing shi shan lang haizei" (I used to be a mountain wolf and sea robber). In Bei Dao and Li Tuo (eds.), Qishi niandai (The Seventies). Hong Kong: Oxford University Press, 359-381.

Denzin, Norman. 1978. "The comparative life history method." In Norman Denzin (ed.), The Research Act. New York: McGraw Hill, 214-255. 
Dong, Guoqiang, and Andrew G. Walder. 2011. "Local politics in the Chinese Cultural Revolution: Nanjing under military control." The Journal of Asian Studies 70, 425-447.

Evans, Harriet. 1997. Woman and Sexuality in China: Female Sexuality and Gender since 1949. Cambridge: Polity.

Fei, Hsiao-Tung. 1992. Xingxing chong xingxing (Going and Going). Ningxia: People's Publishing House.

Figes, Orlando. 2007. The Whisperers: Private Life in Stalin's Russia. New York: Metropolitan Books.

Finnane, Antonia. 2008. Changing Clothes in China: Fashion, History, Nation. New York: Columbia University Press.

Fisher, Jill A. 2002. "Tattooing the body, marking culture." Body \& Society 8(4), 91-107.

Fitzpatrick, Sheila, and Alf Lüdtke. 2009. "Energizing the everyday: on the breaking and making of social bonds in Nazism and Stalinism." In Michael Geyer and Sheila Fitzpatrick (eds.), Beyond Totalitarianism: Stalinism and Nazism Compared. New York: Cambridge University Press, 167-301.

Foucault, Michel. 1981. "Omnes et singulatim: towards a criticism of 'political reason'." In Sterling M. McMurrin (ed.), The Tanner Lectures on Human Values. Cambridge: Cambridge University Press, 223-254.

Guillain, Robert. 1957. The Blue Ants: 600 Million Chinese under the Red Flag (Mervyn Savill (trans.)). London: Secker and Warburg.

Guo, Dehong, Wang Haiguang and Han Gang. 2009. Zhonghua renmin gongheguo zhuanti shi gao (3): shi nian fengyu (Thematic History of the People's Republic of China (3): Ten Years of Turmoil). Sichuan: People's Publishing House.

He, Shu. 2010. Wei Mao zhuxi er zhan: wenge shiqing Chongqing da wudou shilu (Fighting for Chairman Mao: Records of Chongqing Armed Conflict during the Cultural Revolution). Hong Kong: Joint Publishing.

Hellbeck, Jochen. 2006. Revolution on My Mind: Writing a Diary under Stalin. Cambridge, MA: Harvard University Press.

Honig, Emily, and Hershatter Gail. 1988. Personal Voices: Chinese Women in the 1980s. Stanford, CA: Stanford University Press.

Ip, Hung-Yok. 2003. "Fashioning appearances: feminine beauty in Chinese Communist revolutionary culture." Modern China 29(3), 329-361.

Jarvis, Lucy. 1973. The Forbidden City [documentary film]. N.B.C. Television.

Jin, Chunming. 1995. "Wenhua dageming” shigao (A Manuscript of the History of the "Great Cultural Revolution”). Sichuan: People's Publishing House.

Jin, Dalu. 2011. Feichang yu zhengchang: Shanghai wenge shiqi de shehui shenghuo (Ordinary and Extraordinary: Lives and Society in Shanghai in the Cultural Revolution). Shanghai: Ci Shu Publishing House.

Klemperer, Victor. 2000. The Language of the Third Reich: Lti, Lingua Tertii Imperii: A Philologist's Notebook (Martin Brady (trans.)). London: Athlone Press.

Knopp, Guido. 2002. Hitler's Children (Angus McGeoch (trans.)). Stroud: Sutton.

Kuhn, Philip A. 1999. Jiao hun: 1768 nian Zhongguo yaoshu da konghuang (Calling the Soul: Fear of the Chinese Witchcraft in 1768) (Chen Qian and Liu Yongyi (trans.)). Shanghai: Joint Publishing Company.

Kunz, Jean Lock. 1996. "From Maoism to ELLE: the impact of political ideology on fashion trends in China." International Sociology 11(3), 317-335.

Lee, H.Y. 1978. The Politics of the Cultural Revolution. Berkeley, CA: University of California Press.

Lei, Yi. 2000. "Richang shenghuo yu lishi yanjiu" (Everyday life and historical studies). Shixue lilun yanjiu 3, 121-27.

Li, Danhui, and Shi Yun. 2008. Nan yi jixu de "jixu geming" - cong pi Lin dao pi Deng (1972-1976) (Difficult to Continue the "Continuous Revolution”: From Criticizing Lin to Criticizing Deng (19721976)). Hong Kong: Chinese University of Hong Kong Press. 
Li, Ling. 2008. "70 niandai: woxinzhong de suipian” (The seventies: fragments in my heart). In Bei Dao and Li Tuo (eds.), Qishi niandai (The Seventies). Hong Kong: Oxford University Press, 235-256.

Li, Xun. 2015. Geming zaofan niandai: Shanghai wenge yundong shi gao (Days of the Revolutionary Rebels: A Manuscript of the History of the Cultural Revolution Movement in Shanghai). Hong Kong: Oxford University Press.

Liu, Dong. 2005. "Heitian de gushi - 'wenge' shidai de dixia shouchao ben" (Stories of the dark days: underground manuscripts of the Cultural Revolution era). Kaifang shidai 6, 144-157.

Liu, Qingfeng (ed.). 1996. Wenhua da geming: lishi zhenxiang yu yanjiu (The Great Cultural Revolution: Historical Facts and Research). Hong Kong: Chinese University Press.

Liu, Zhijun. 2002. "Ying pian 'gugong' yin chu de kuaguo qingyuan" (The transnational love brought about by the film "Forbidden City"). Zong Heng 7, 39-41.

Ma, Hong. 1979. "Zenyang liyong Xianggang wei jiasu woguo sige xiandaihua jianshe fuwu" (How to take advantage of Hong Kong to speed up the realization of the four modernizations). Jingji yanjiu cankao ziliao 39, 15-16.

MacFarquhar, Roderick. 1981. The Origins of the Cultural Revolution (Vols. 1 and 2). Cambridge: Cambridge University Press.

MacFarquhar, Roderick, and Michael Schoenhals. 2006. Mao's Last Revolution. Cambridge, MA: Harvard University Press.

Mei, Zhencai. 2007. "Wenge shi cijian zheng lishi" (The Cultural Revolution poetry witnesses history). In Song Yongyi (ed.), Wenhua da geming: lishi zhenxiang yu jiti jiyi (The Cultural Revolution: The Real History and Collective Memory). Hong Kong: Tianyuan shuwu, 635.

Obukhova, Elena, Ezra W. Zuckerman and Jiayin Zhang. 2014. "When politics froze fashion: the effect of the Cultural Revolution on naming in Beijing." American Journal of Sociology 120(2), 555-583.

Perry, Elizabeth J., and Xun Li. 1997. Proletarian Power: Shanghai in the Cultural Revolution. Boulder, CO: Westview Press.

Pickowicz, Paul G., and Andrew G. Walder (eds.). 2006. The Chinese Cultural Revolution as History. Stanford, CA: Stanford University Press.

Qing, Qiuzi. 2006. Zheteng shinian (Ten Years of Up-side-down). Anhui: Literature and Art Publishing House.

Rosen, Stanley. 1981. The Role of Sent-down Youth in the Chinese Cultural Revolution: The Case of Guangzhou. Berkeley, CA: University of California Press.

Ryder, Norman B. 1965. "The cohort as a concept in the study of social change." American Sociological Review 30(6), 843-861.

Scott, James C. 2008. "Everyday forms of resistance." The Copenhagen Journal of Asian Studies 4(1), 33-62.

Shan, Shaojie. 2001. Mao Zedong de zhizheng chunqiu (The Ruling Years of Mao Zedong). Taipei: Lianjing Publishing and Public Utility.

Shang, Yewen. 1972. "Fuwu ye yao genghao de wei gongnongbing fuwu" (The service industry must serve the workers, peasants and soldiers better), Renmin ribao, 5 April.

Siu, Helen 1989. Agents and Victims in South China: Accomplices in Rural Revolution. New Haven, CT: Yale University Press.

Sun, Peidong. 2010. “Kujiaoshang de jieji douzheng: wenge shiqi Guangdong de 'qizhuang yifu' yu guojia guixun" (Class struggle on the leg opening: "bizarre clothes" and state discipline in Guangdong during the Cultural Revolution). Kaifang shidai 6, 84-101.

Sun, Peidong. 2012. "Zongtizhuyi beijing xia de shishang: 'wenge' shiqi Guangdong minzhong zhuozhuang shishang fenxi" (Fashion under totalism: an analysis of everyday clothes and fashion in Guangdong in the Cultural Revolution). Kaifang shidai 4, 92-113.

Sun, Peidong. 2013. Shishang yu zhengzhi: wenge shiqi Guangdong minzhong richang zhuozhuang shishang (Fashion and Politics: Everyday Clothes and Fashion in Guangdong, 1966-1976). Beijing: People's Publishing House. 
Tang, Shaojie. 2003. Yi ye zhi qiu: Qinghua daxue 1968 nian "bairi da wudou” (An Autumn Leaf: The "Hundred Days of Armed Struggle" at Tsinghua University in 1968). Hong Kong: Chinese University of Hong Kong Press.

Teiwes, Frederick C., and Warren Sun. 2007. The End of the Maoist Era: Chinese Politics during the Twilight of the Cultural Revolution, 1972-1976. New York: M.E. Sharpe.

Thornton, Patricia M. 2002. "Framing dissent in contemporary China: irony, ambiguity and metonymy." The China Quarterly 171, 661-681.

Tilly, Charles. 1991. "Domination, resistance, compliance ... discourse." Sociological Forum 6(3), 593-602.

Walder, Andrew G. 2009. Fractured Rebellion: The Beijing Red Guard Movement. Cambridge, MA: Harvard University Press.

Wang, Nianyi. 1988. Dadongluan de niandai: 1949-1976 nian de Zhongguo (A Time of Great Upheavals: China from 1949 to 1976). Henan: People's Publishing House.

Wang, Shaoguang. 1995a. Failure of Charisma: The Cultural Revolution in Wuhan. Oxford: Oxford University Press.

Wang, Shaoguang. 1995b. "Tuokuan wenge yanjiu de shiye" (Broaden the horizon of Cultural Revolution research). 21st Century 5, 92-102.

Wang, Shaoguang, Huang Wansheng, Shan Shilian, Cai Xiang, Jin Dalu, Xu Junzhong and Lao Tian. 2013. "70 niandai Zhongguo" (China in the seventies). Kaifang shidai 1, 5-95.

$\mathrm{Xu}$, Bei. 2006. "Wenge shiqi de wuzhi wenhua he richang shenghuo zhixu" (Material culture and the order of everyday life during the Cultural Revolution). Modern China Studies 3, 23-34.

$\mathrm{Xu}$, Lan. 1999. "Nüda de laodong shenghuo" (Working life at the women's university). In Yan Mingshi (ed.), Yan shui qing: jinian Yanan Zhongguo nüzi daxue chengli liushi zhounian (Warm Feelings towards the Yan River: A Commemoration of the Sixtieth Anniversary of the Establishment of the Chinese Women's University in Yanan). Beijing: Chinese Women's Publishing House, 252-254.

Yan, Yunxiang. 2010. "The Chinese path to individualization." The British Journal of Sociology 61 (3), 489-512.

Yang, Mayfair Mei-hui. 1999. Spaces of Their Own: Women's Public Sphere in Transnational China. Minneapolis, MN: University of Minnesota Press.

Zhai, Yongming. 2008. "Qing chun wu nai” (Helpless youth). In Bei Dao and Li Tuo (eds.), Qishi niandai (The Seventies). Hong Kong: Oxford University Press, 257-279.

Zhang, Baojun, and Zhao Ziyong. 1997. "Wenhua dageming shiqi neidi yu Xianggang de jingji guanxi" (Economic relations between mainland China and Hong Kong during the Cultural Revolution). Zhongguo dangshi yanjiu 2, 45-50.

Zhang, Hanzhi. 1994. Feng yu qing: yi fuqin, yi zhuxi, yi Guan Hua (Love through Thick and Thin: Remembering Father, Remembering the Chairman and Remembering Guan Hua). Shanghai: Literature and Art Publishing House.

Zhang, Hong. 2004. "Geming nü zhuang” (Revolutionary women's clothes). Nanfeng chuang 9, 86.

Zhu, Dake. 2006. "Ling yu xiu de hongse fengqing” (Red style on collars and sleeves). Hua cheng 4, $107-110$. 